\title{
Openness, Similarity in Export Composition, and Income Dynamics
}

\author{
LUCA DE BENEDICTIS* \& LUCIA TAJOLI** \\ ${ }^{*}$ DIEF, University of Macerata, Italy, ${ }^{* *}$ Dipartimento di Ingegneria Gestionale, Politecnico di \\ Milano, Italy
}

\begin{abstract}
A relevant share of the theoretical and empirical analysis on economic growth has been devoted to finding a specific role for international trade in reinforcing countries' growth rates. Not as much attention has been dedicated to the role of sectoral composition of export in influencing the effect of trade on income convergence. In this paper we look at this issue along the line of research on multiple regimes and convergence clubs, considering how openness and similarity in export composition among countries can induce convergence in income levels among the same countries. We apply our analysis to the catching-up of income levels of Central and Eastern Europe Countries to the EU benchmark. We explicitly consider the sectoral export patterns of the CEECs by comparing them to those of the 15 old members of the EU, focusing on countries' specialization as suppliers for the EU market. Our main result is that similarity in export composition has a positive, significant and nonlinear impact on catching-up. Results are robust to controlling for openness and country-size and for investment, schooling, and the quality of institutions.
\end{abstract}

KEY WORDS: CEECs, transition, growth, semiparametrics

\section{Introduction}

In this paper, we examine the much-debated relationship between trade and economic growth from a specific viewpoint: the role of export composition in fostering convergence between a group of trading countries.

A wide range of theoretical approaches - from post-Keynesian models of trade and growth to endogenous growth models - suggest that the link between a country's growth rates and its level of openness hinges on the characteristics of the country's trade pattern. But in spite of the suggestions coming from theoretical models, most of the empirical literature limits the 
analysis to the effect of aggregate openness indicators on growth. Here we try to partially fill the gap between the theoretical propositions and the empirical analysis, by explicitly considering trade structure as a determinant of growth. More specifically, we test whether different or similar export compositions affect the speed of catching-up, on the basis that more than openness per se, what should matter for convergence is a country's export pattern relative to its main partners.

The empirical exercise focuses on the recent EU enlargement to the Central-Eastern European countries (CEECs). This integration process displays interesting dynamics both in terms of GDP and trade structures. Since the very early phases of transition, the CEECs opened up significantly to trade, especially toward the $\mathrm{EU}^{1}$ changing sharply both the geographic and sector orientation of their trade flows. Such a change was not uniform, bringing about different trade structures among the CEECs. Eventually, the CEECs also experienced a catching up process toward the EU income levels, even if the distance from the 15 older EU member countries is, in this respect, still very large.

The observation that the countries moving toward the EU trade structure are among the most advanced ones both in terms of their transition process and per capita income levels and in terms of their institutional integration with the EU leads to the hypothesis of a correlation between convergence in export composition and convergence in income levels. Testing such hypothesis is the aim of this paper. In the next section we suggest how similarity in export composition and income convergence may be linked, while the section after defines the similarity index used in the analysis and presents the empirical evidence for the EU and the CEECs on openness and convergence. The fourth section contains the econometric results of the multivariate parametric and semiparametric regressions, and discusses robustness issues and the evidence of nonlinearity in the partial effect of similarity in export composition on income convergence. The fifth section concludes.

\section{How are Trade Structure and Income Dynamics Related?}

After a wave of empirical literature on openness and growth, which was largely anecdotal and used very simple cross-country estimation techniques, the work developed in the 1990s tried to address some of the shortcomings of the previous literature, establishing the link between trade and growth on firmer grounds. The papers by Dollar (1992), Sachs and Warner (1995), Edwards (1998), Frankel and Romer (1999) are just a sample of the studies finding a positive relation between openness indicators and growth rates amplifying the consensus on the positive effect of trade on growth.

But this more recent wave of literature was heavily disputed too, on the basis that the empirical results were not robust to changes in the time period or group of countries being analyzed. The use of different indicators was 
criticized, as it implicitly assumes different mechanisms through which trade influences economic performance, without explicitly addressing this important point (Hallak \& Levinsohn, 2004). Part of the literature linking trade and growth rates sees openness as inversely related to distortions in the economy, and as an indicator of the correct functioning of the market and price mechanism, leading to suitable investment decisions and therefore to growth (Baldwin, 2004). While this mechanism could be very relevant, especially in many less developed countries, the openness indicators may in fact capture a range of different and deeper effects. The main point of the criticism to the use of an array of aggregate openness indicators is the '... suspect that the relationship is a contingent one, dependent on a host of country and external characteristics' (Rodriguez \& Rodrik, 2000) which are not correctly captured by the analysis.

A closer look to the theoretical models shows that countries' interdependence affects growth patterns and the nature and speed of convergence in more fundamental ways. As stressed by the works of Slaughter (1997) and Ventura (1997), trade impacts on growth and convergence paths by affecting factors' prices, and therefore factors' accumulation. Such an impact depends on a country's situation with respect to its trading partners, and different circumstances may well bring about different dynamic effects. One of these circumstances is a country's specialization and trade structure. In order to link trade structure and convergence, Slaughter (1997) decomposes per capita income convergence into a 'factor price effect' and 'factor endowment effect", as simple accounting shows that per capita income is a combination of both factor prices and factor quantities. Both the order of magnitude and the sign of such effects are sensitive to trade patterns.

This is where we take off, focusing on the different effects on growth rates and convergence of different trade structures. We look at convergence along the line of research on multiple regimes and club convergence opened by Durlauf and Johnson (1995) and Quah (1997), and surveyed in Durlauf and Quah (1999) and in Durlauf (2003). As for trade and income convergence, we move from the analyses of Slaughter (1997) and from the approach of Ben-David and Loewy (1998), explicitly considering how similarity in trade structure, measured by export sectoral composition, can induce convergence in income levels among countries through different channels suggested by the economic theory on growth.

The first channel links similarity in trade structure and productivity improvements, as trade in similar or identical industries allows exploiting different externalities that can positively affect growth rates. Technological and knowledge spillovers are unlikely to affect all sectors evenly (van de Klundert \& Smulders, 1996) and are more likely to occur within the same or technologically similar industries. Therefore, the scope for international technological spillovers is enhanced if trade structures overlap. Intraindustry trade exploits economies of scale, enhancing productivity, which can accelerate the growth rate along the transition path. Production sharing 
and processing trade - very important phenomena in the EU-CEECs trade relations - increase the likelihood of spillovers and the access to advanced technology by the CEECs. Similar export patterns can also increase average productivity through increased competition for the firms involved, as suggested by Ben-David and Kimhi (2000). Stronger competition, both at home and abroad, makes the absorption of foreign knowledge and ideas crucial, and allows only the more productive firms to survive. If this is the case, it might not be trade per se that matters if there is no overlap in specialization. Instead, similar export patterns will increase competition between countries, enhancing the positive competition effects. The effects of increased productivity are directly connected to factors accumulation. If growth and convergence are driven by factors accumulation and incentives to accumulate depend on returns and prices (Young, 1991; Ventura, 1997), similar trade specialization brings about a similar incentive structure and can enhance convergence.

The second channel connecting export similarity and convergence enhances the demand-side effects, somehow along the lines first suggested by Linder (1961) and more recently developed by Markusen (1986). The positive effects of trade on growth rates rely to a large extent on trade volumes to exploit the scale effects built in endogenous growth models (Rivera-Batiz \& Romer, 1991). Therefore, the positive consequences of trade are more likely to take place if the goods exported by a country are matched by a large and growing demand in its export market. If similarity in trade structures reflects this matching of supply and demand, which enhances the (static and dynamic) gains from trade, a lagging country can speed up its catching-up process if its trade structure becomes more similar to the one of advanced countries, as this will expand the opportunities offered by trade.

Finally, there is a third channel connecting export similarity and catchingup. The economic literature shows that specialization patterns have a sizable effect on business cycle transmission between countries: countries with stronger trade linkages tend to have more highly correlated business cycles, and differences in production patterns imply different degrees of exposure to common sectoral stochastic developments (Imbs, 1999, 2004; Kose \& Yi, 2006). In this perspective, for a country having an export composition similar to the one of its trading partners means being similarly exposed to business cycle phases and to shocks, reducing the amount of divergence factors and possibly enhancing convergence.

In spite of these theoretical suggestions, very few studies explicitly consider the role of trade structure in determining countries' growth and catching-up. A difficulty in performing this kind of empirical test is in finding a good representation of the trade structure comparable across countries, and in linking a measure of disaggregated trade flows to aggregate macroeconomic variables. The few existing works consider the role of concentration versus diversification of exports (Imbs \& Wacziarg, 2003), or 
exports of agricultural goods and raw materials (Sachs \& Warner, 1999), to test the risk-exposure-and-growth hypothesis (Lederman \& Maloney, 2003). Feenstra and Rose (2000) find a strong relation between what they call advanced export structures and high productivity levels and fast growth rates, having in mind the trade-productivity-growth link. Crespo Cuaresma and Wörz (2005) test whether exports in technology intensive industries have a higher potential for positive externalities, and they find a significant effect in the case of developing countries. Bensidoun et al. (2001) also find that the growth effects of trade depend on the type of products countries are specialized in, and in particular what matters is the adaptation of specialization patterns to the dynamic of international demand. In general, when a trade structure variable is considered, the empirical evidence confirms what the theory suggests, that trade structure - rather, or at least more precisely, than trade per se - can affect income convergence between countries (Rodrik et al., 2005).

\section{GDP Growth, Openness and Trade Structure Dynamics}

\section{Catching-up and Transition in the CEECS}

The specific contribution of this paper is that - rather than trying to assess whether a specific trade structure is enhancing or hampering the catching-up process - we test whether having a similar export composition brings about income convergence within a group of countries. In other words, we assume that a particular trade structure can influence positively or negatively convergence relatively to the group of countries you are converging to. Therefore we choose and define carefully the sample of countries we want to examine. Emphasizing similarities and referring to a benchmark specific for the countries selected made up by the main export market allows us to refrain from using a sector classification that arbitrarily divides exporting sectors into groups with different impacts on growth rates and convergence.

We focus our attention on the process of economic integration between the CEECs and the EU, because this case presents a number of interesting characteristics. The liberalization of trade flows between the CEECs and the EU was pursued immediately after the collapse of the centralized systems in central Europe and played a key role in the integration process of the area. Even in the very early phases of transition, when experiencing negative GDP growth rates, the CEECs shifted their trade structures to a remarkable extent, unobserved in non-transition economies, both in terms of exporting industries and in terms of trading partners (Landesmann, 2003). The EU quickly became their main export market, as the CEECs and the EU signed the so-called Europe Agreements in the early 1990s, starting a process of preferential trade liberalization and phasing out of their reciprocal tariffs. These agreements eventually led to the application of the CEECs for EU membership. 
For the CEECs, the EU represented a natural target also in terms of standards of living, but not surprisingly the catching-up process of the CEECs in terms of growth and income levels was more difficult and required the transition to be more advanced. It was only in the mid-1990s that the CEECs' economies reverted to positive growth rates and started to converge toward the EU both in terms of productivity and in terms of per capita income. Since then, on average the CEECs' GDP growth rates were higher than the EU members' growth rates.

The convergence process was very uneven across countries, as their per capita income levels compared to the EU average show (see Table 1). If we measure the CEECs income per capita in purchasing power standards relative to the EU-15 average income per capita, we observe a positive trend in the second half of the 1990s for most of them, showing that the gap has been gradually narrowing. The catching-up appears especially fast for Slovenia, followed by Slovakia, two countries with very different starting points. Slovakia was in the poorest countries' group, having in 1993 an income per capita equal to 37.7 per cent of the EU average, while Slovenia was at 58.2 per cent, ranking very close to the top. The path followed by the Czech Republic, which in 1993 had the income level closest to the EU average (60.8 per cent) among the CEECs, is very irregular. Bulgaria and Romania, ranking at the bottom of the group in 1993, show a positive trend toward the EU average income only from 1997 onward.

These differences reflect a number of factors, such as the macroeconomic policies followed in the transition period, different investment (both domestic and foreign) rates, different rates of technological catching-up,

Table 1. GDP per capita and average annual catch-up rate for the CEECs

\begin{tabular}{|c|c|c|c|c|c|}
\hline & \multicolumn{2}{|c|}{$\begin{array}{l}\text { GDP per capita } \\
(E U 15=100) \\
\end{array}$} & \multicolumn{3}{|c|}{$\begin{array}{c}\text { Average annual catch-up rate for the CEECs } \\
(\%)\end{array}$} \\
\hline & 1993 & 2002 & $1993-2002$ & $1993-97$ & $1998-2002$ \\
\hline Bulgaria & 27.9 & 26.4 & 0.21 & 1.18 & -0.77 \\
\hline Czech Republic & 60.8 & 61.9 & -0.31 & -1.27 & 0.65 \\
\hline Estonia & 30.6 & 40.1 & -1.61 & -1.64 & -1.58 \\
\hline Hungary & 44.7 & 53.4 & -1.7 & -0.47 & -2.93 \\
\hline Latvia & 26.6 & 34.8 & -0.61 & 0.47 & -1.69 \\
\hline Lithuania & 33.2 & 39.1 & 0.08 & 1.80 & -1.64 \\
\hline Poland & 34.6 & 41.7 & -1.36 & -2.28 & -0.44 \\
\hline Romania & 25.8 & 26.5 & -0.17 & -0.25 & -0.09 \\
\hline Slovakia & 37.7 & 47.1 & -2.03 & -2.55 & -1.50 \\
\hline Slovenia & 58.2 & 69.0 & -3.45 & -3.87 & -3.03 \\
\hline
\end{tabular}

Notes: A negative catch-up rate indicates that the income gap between a country and the EU average is falling while a positive rate means that this gap is widening. The catch-up rate is calculated as

$$
\left[\left(G D P_{i t}-G D P_{e t}\right)-\left(G D P_{i(t-1)}-G D P_{e(t-1)}\right)\right] /\left(G D P_{i(t-1)} / G D P_{e(t-1)}\right) \times 100
$$

where $G D P_{i t}$ is the level of GDP per capita in PPS for country $i$ at time $t$ and $G D P_{e t}$ is the average value for EU15. See also European Commission (2004), ch.2. 
affected by the country's skill endowment and absorption capacity. But the different growth rates might also reflect differences in the industrial structure and in the weight of sectors having different dynamics in productivity.

As far as openness, with few exceptions, the CEECs are classified as open economies since 1990-92. In their updating of the Sachs and Warner (1995) openness indicator, Wacziarg and Welch (2003) classify only Estonia and Romania as closed economies. This classification does not follow uniquely from the CEECs' tariff levels, which are differentiated, going from an average of about 17 per cent for Bulgaria to 1 per cent for Estonia. Considering other openness indicators, such as the import and export flows over GDP, all the CEECs appear to be very open to trade, with the smallest economies being naturally the most open. However, for these countries, the comparable aggregate openness indicators hide large differences in export composition.

\section{Defining Similarity in Trade Structures}

As mentioned, we do not want to limit the analysis to the link between aggregate openness indicators and income convergence. Instead, we want to emphasize the role of specific trade structures on growth. The existing literature shows that the CEECs trade patterns changed quite dramatically since the early phases of transition: the CEECs' export structure has moved in different directions, with some countries quickly upgrading their specialization, while other countries are lagging behind (Landesmann, 2003). Normally, evidence on changes in trade structures is presented through a large number of indicators and presenting an array of sectoral specialization indices, but it is not straightforward to find a suitable description of such complex changes with a measure that can be used in empirical exercises. Following De Benedictis and Tajoli (2007), we build an index of changes in export composition for ten CEECs: Bulgaria, the Czech Republic, Estonia, Hungary, Latvia, Lithuania, Poland, Romania, the Slovak Republic, and Slovenia.

We examine the evolution of trade similarity over time - from 1993 to 2002 - measuring the distance of a country's export composition from a given benchmark, using sectors' export shares. We define a self-similarity index (how the export composition of an EU member-to-be has changed with respect to the beginning of the transition process) and $E U$-similarity index (if and how the export composition of an EU member-to-be has changed with respect to the EU export composition), using the Bray-Curtis distance index defined as: ${ }^{2}$

$$
d_{x y}=\frac{\sum_{i}\left|x_{i}-y_{i}\right|}{\sum_{i}\left(x_{i}+y_{i}\right)}
$$

where $x$ and $y$ are two different countries identified by $n$ sectoral export shares (the value of exports in sector $i$ over the value of total exports), given 
by $x_{i}$ and $y_{i}$. To move from the Bray-Curtis distance index to a similarity measure we take

$$
s_{x y}=1-d_{x y}
$$

where if $s_{x y}=1$ the export patterns are identical and if $s_{x y}=0$ the patterns show no overlap. In defining EU-similarity, country $x$ is a CEEC and $y$ is the EU benchmark; in defining self-similarity, country $x$ is a CEEC considered at any subsequent time period and $y$ is always the initial year considered, 1993.

The self-similarity and EU-similarity indices for the CEECs are presented in Figure 1, where self-similarity is measured along the vertical axis and EUsimilarity along the horizontal axis. The starting point, 1993, is for each country at the top of the figure, depicted by a labeled square, and the length of the vertical segments indicate how much the country changed its export composition with respect to 1993. Every circle indicates a subsequent year. If the line progressively moves rightward, the country's export composition becomes more similar to the EU export composition, with a value of 1 of the index showing perfect overlap in exports' composition.

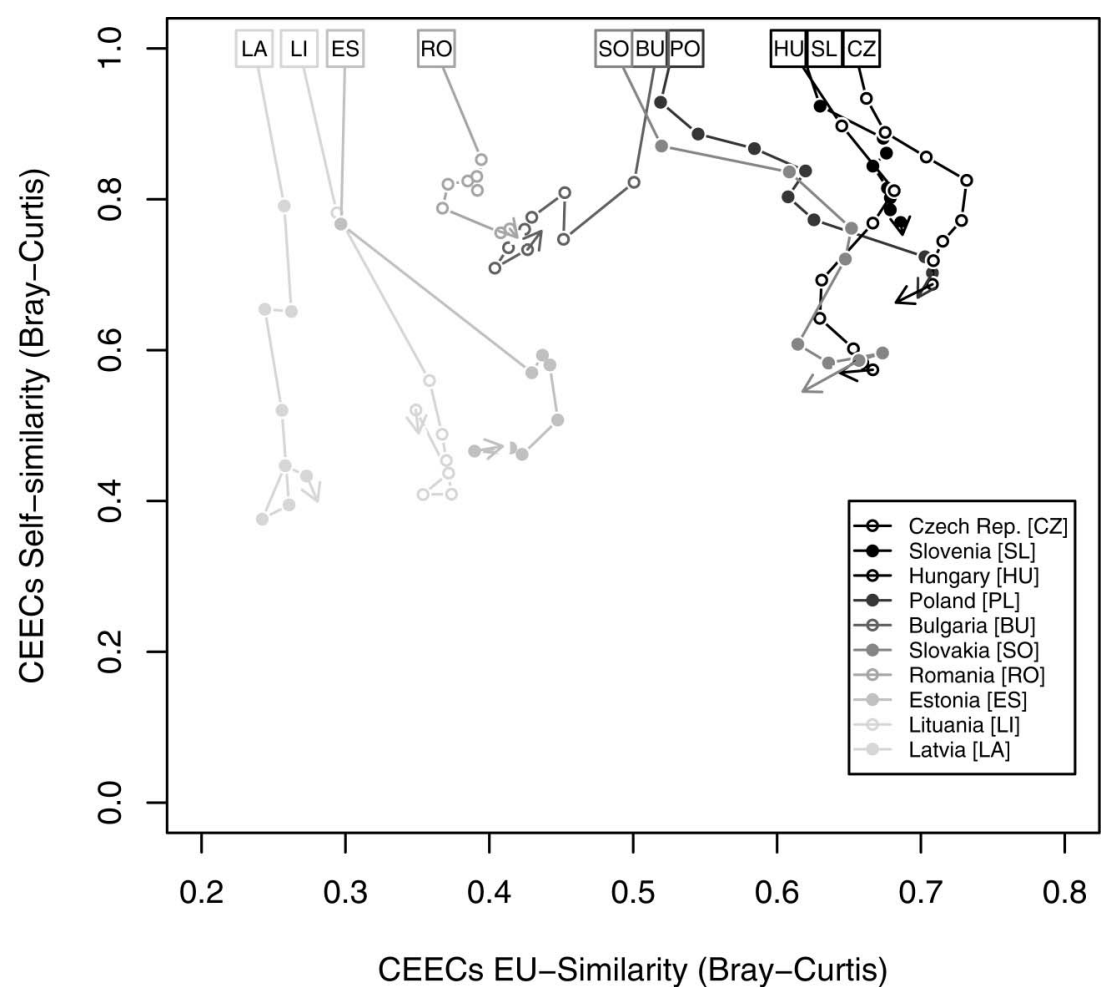

Figure 1. CEECs self-similarity and EU-similarity, 1993-2002. Source: Authors' elaborations on Eurostat Comext database 
The figure shows remarkable differences across countries, in both the similarity dimensions examined. The three Baltic republics represent a group on their own, as their export composition has changed the most since 1993. These countries in 1993 were very different from the EU both in terms of exports and of income per capita, but while they show very little or no convergence toward the EU in terms of exports, with respect to income their catching up was remarkable, even if a large gap still persists. Romania and Bulgaria instead are the countries whose export composition changed the least in the past decade, and following a very irregular path. Bulgaria also shows divergence in its export composition with respect to the EU, and Romania shows some convergence only in the last few years. The remaining five countries overall changed their export composition in the EU direction, even if to quite different extents. Poland is the country that converged the most toward the EU export composition and it is now the most similar country in this respect. Hungary instead followed a very irregular path, like Slovakia, even if the two countries had different starting points both in terms of export composition and income. For this converging group, convergence in the export composition seems to slow down in the last years. Summing up, there is no generalized trend in the changes observed in the export composition, confirming that the CEECs followed different paths in restructuring their economies, just like they recorded different macroeconomic performances.

The observation of the data on GDP growth rates of the CEECs together with Figure 1 is suggestive of a possible relationship between converging trade structures and income convergence: the countries whose exports' paths are less convergent toward the EU are also the countries lagging behind in terms of incomes. The existence of such a relationship can be properly explored and should be tested empirically, to test its robustness and the possibility of observing a spurious relation affected by other factors, and to infer a possible direction of causality.

\section{Kernels, Bivariate Densities and Multiple Regimes}

An efficient way of extracting information on the structural characteristics of the variables under scrutiny and on their evolution along time is to follow Quah (1997) in the use of kernel densities. Since we want to emphasize if and how trade openness and the similarity of sectoral export composition to the EU are linked to per capita GDP changes, we analyze the joint distribution of openness, and of EU-similarity, and per capita GDP.

Figure 2 plots several estimated kernel densities mapping the bivariate distribution of pooled per capita GDP of the CEECs with respect to openness and EU-similarity. In the upper part of Figure 2, the twodimensional kernels show two main modes oriented at the edges of the per capita GDP spectrum, more or less at the same level of openness. A third minor mode depicts a group of observations with a joint distribution defined 

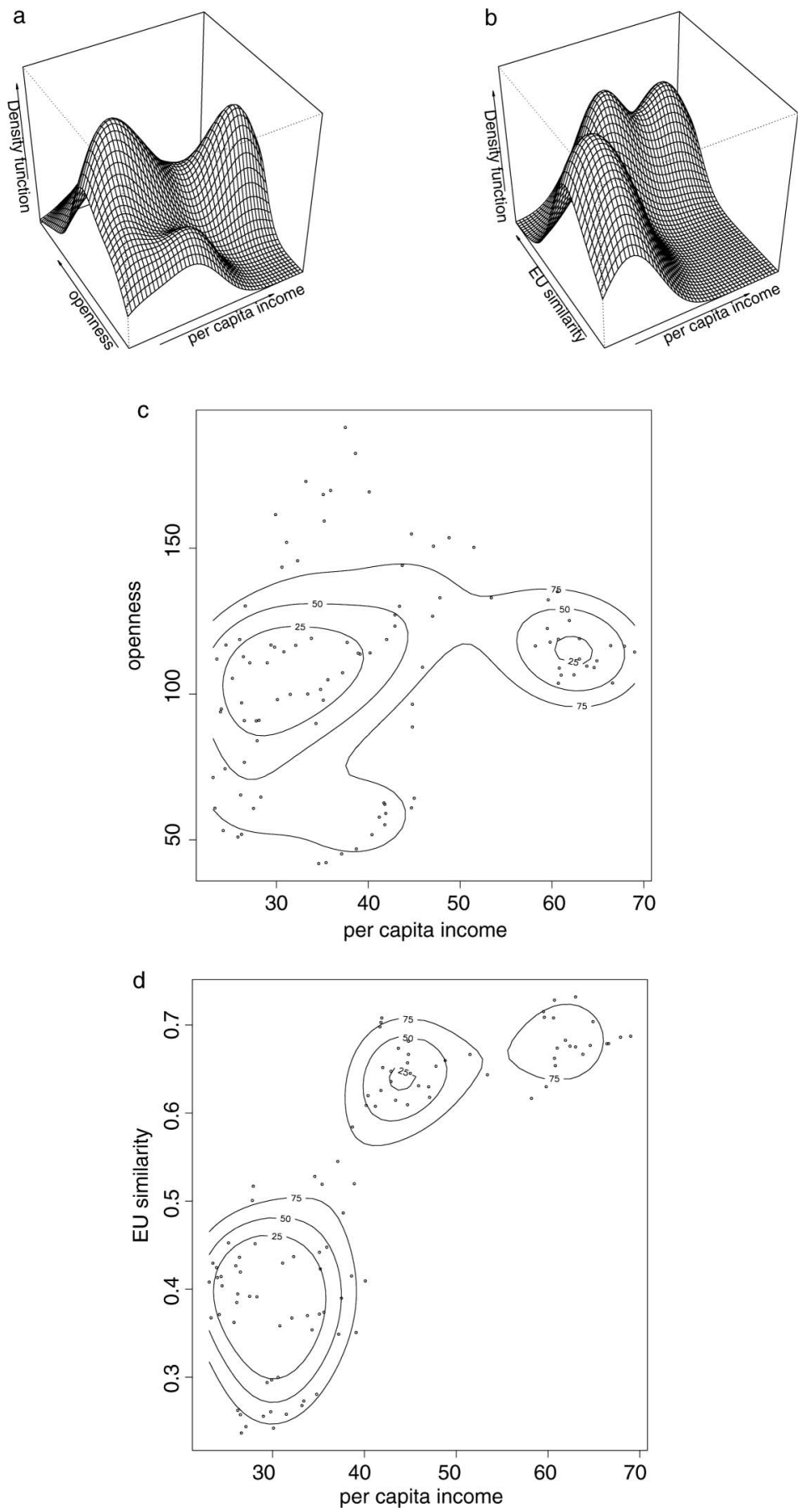

Figure 2. Kernel densities, multiple regimes and conditional convergence. Source: Authors' elaborations on Eurostat data 

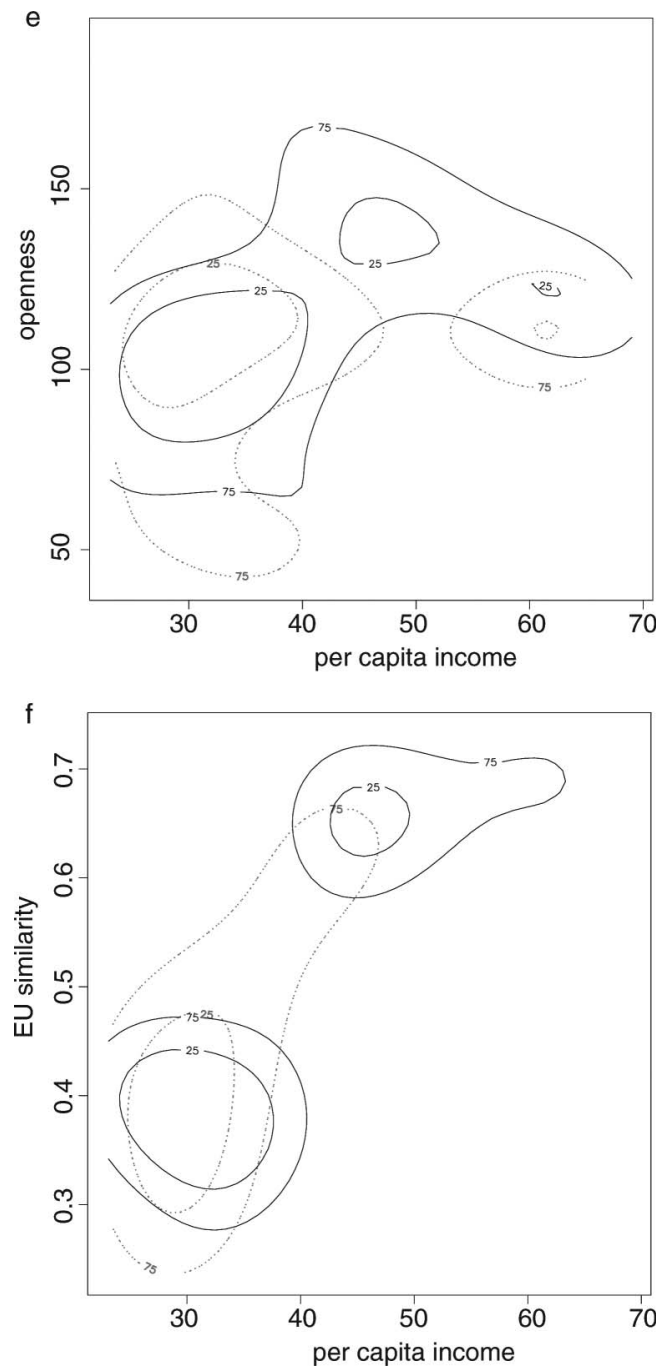

Figure 2. (Continued)

by intermediate levels of per capita GDP and a very low level of openness. As for as the joint distribution of per capita GDP and EU-similarity, a clear positive relationship emerges. It is represented by a three-modal distribution, where the modes identify three groups of observations characterized respectively by a relative low per capita GDP and a relative low EUsimilarity, a medium per capita GDP and a medium EU-similarity, and an high per capita GDP and an high EU-similarity. The modes are however not perfectly aligned along the main diagonal, inducing the suspicion of a nonlinear relation between the two variables. 
The central part of the same figure illustrates an alternative form of displaying through contours the bivariate density estimates shown in the first row. ${ }^{3}$ In the case of openness, the contour-plot shows the bimodality of the joint-distribution and gives evidence of a relevant aspect of the data: 'rich' countries have a level of openness above 100, while 'poor' countries have a level of openness that ranges all along the spectrum of the variable. From a global point of view, no clear relationship emerges. In the case of EU-similarity, the contour-plot shows a clearer path: the relation is positive, with some evidence of nonlinearity. The relation between these variables is better characterized by using a regression function, as will be shown in the following section.

The contour-plot can be used to show how the bivariate distributions have changed over time. After dividing the data into two groups of observations, one for the years between 1993 and 1997, and the second one for the years 1998-2002, we plotted and compared density estimates for the two time periods identified above. This is done in the bottom part of Figure 2. The shape of each density estimate is defined by two contours containing 75 per cent and 25 per cent of the observations, and the two densities are superimposed to show the evolution of the three variables over the decade. The dynamics of the openness kernel density shows an upward shift of the joint distribution, a third mode appears, displaying the emergence of a number of country-observations with a per capita GDP around 50 per cent of the EU average and with a level of openness close to 150. In terms of EU-similarity, the main change emerging in the late 1990s is a double or 'twin peaks' regime: the evidence of two different clubs of countries characterized by very different levels of per capita GDP and EU-similarity is remarkable, and so are the changes observed in the group of countries converging toward the EU in terms of per capita GDP and EU-similarity. We will also test these dynamics in a multivariate regression framework in the next section.

\section{Econometric Results}

\section{The Starting Point}

The basic expression of the regression we estimate for the ten CEECs over the period $1993-2003$ to test the role of openness and similarity in trade structures in the catching-up process is the following:

$$
\begin{aligned}
\ln G D P_{j t}= & \beta_{0}+\beta_{1} \ln E U \text {-similarity }_{j t}+\beta_{2} \ln S E L F \text {-similarity } \\
& +\beta_{3} \ln \text { openness }_{j t}+\mathbf{X}_{j t} \gamma+u_{j t}
\end{aligned}
$$

where $G D P_{j t}$ is per capita GDP measured in purchasing power standards in percentage of the average EU income per capita. This variable measures 
directly the catching-up process, and the increase in its value indicates that the gap is narrowing.

$E U$-similarity ${ }_{j t}$, which is our main variable of interest, is the $s_{x y}$ index measuring the similarity between the CEECs and the EU export composition, and an increase in this index indicates that the trade structures are becoming more similar. If our hypothesis that similarities in export composition can foster the catching up process through the different channels discussed in the second section, the correlation between the two measures should be positive.

Self-similarity ${ }_{j t}$ is the index of self-similarity, which should capture the extent of the changes in the CEECs' export composition with respect to their export composition in 1993, the earliest year of transition included in the dataset. Larger changes in the export composition are measured by a lower value of the self-similarity index. A rapid catching-up process could be correlated with a sharp change in the export composition in the case of the CEECs (in our variable with a lower self-similarity). In fact, moving from centralized planning to a market economy, they should be able to better exploit their comparative advantages and change their specialization. Here it is more difficult to anticipate the sign of the relation, because even if it should be negative in the long run (greater changes and lower self-similarity correlated with catching-up), industrial restructuring and resource reallocation in the short run could entail high adjustment costs, with ambiguous effects on the GDP growth rate.

openness $_{j t}$ stands for openness. In the analysis we use two different aggregate measures of openness, the Sachs and Warner (1995) index, ${ }^{4}$ updated by Wacziarg and Welch (2003), or alternatively the trade (Exports + Imports) share of GDP (trade share), measured in purchasing power standards.

$\mathbf{X}_{j t}$ is a matrix of other covariates influencing the catching-up rate. Finally, $u_{j t}$ is an i.i.d. error term. All variables are measured in natural logs in order to facilitate comparisons of partial effects.

Regression results are reported in Table 2. Our base regression only considers EU-similarity and self-similarity as covariates. It confirms the expected positive sign of the correlation between catching-up in income and increased similarity in EU-CEECs trade structure, and the positive correlation between changes in export composition and catching-up in incomes, here shown by a negative sign of the coefficient. The EU-similarity coefficient is significant at the 99 per cent level. Even if the two variables explain 60 per cent of the variance of $G D P$, and the F-test is largely significant, certainly this regression suffers from an omitted variables bias, as income changes depend on a number of different factors not included in the basic functional form. Notwithstanding, these first results are encouraging in indicating that the trade structure might not be irrelevant in affecting the catching-up process.

In columns 2 and 3 of Table 2 we add the two openness indices previously defined. The Sachs and Warner - Wacziarg and Welch index $(S W-W W)$ is a 
Table 2. Pooled data regressions. Dependent variable is country's per capita GDP relative to EU15 per capita GDP

\begin{tabular}{|c|c|c|c|c|c|}
\hline & $\begin{array}{l}O L S \\
\text { (1) }\end{array}$ & $\begin{array}{l}O L S \\
(2)\end{array}$ & $\begin{array}{c}O L S \\
(3)\end{array}$ & $\begin{array}{l}O L S \\
(4)\end{array}$ & $\begin{array}{c}O L S \\
(5)\end{array}$ \\
\hline Intercept & $\begin{array}{c}4.15 \\
(0.05)\end{array}$ & $\begin{array}{c}3.99 \\
(0.77)\end{array}$ & $\begin{array}{c}3.09 \\
(0.26)\end{array}$ & $\begin{array}{c}10.14 \\
(1.79)\end{array}$ & $\begin{array}{l}12.83 \\
(1.60)\end{array}$ \\
\hline EU-similarity & $\begin{array}{c}0.792 \\
(0.06)\end{array}$ & $\begin{array}{c}0.736 \\
(0.065)\end{array}$ & $\begin{array}{r}0.761 \\
(0.06)\end{array}$ & $\begin{array}{c}0.744 \\
(0.054)\end{array}$ & $\begin{array}{c}0.545 \\
(0.058)\end{array}$ \\
\hline Self-similarity & $\begin{array}{r}-0.218 \\
(0.083)\end{array}$ & $\begin{array}{r}-0.202 \\
(0.081)\end{array}$ & $\begin{array}{r}-0.076 \\
(0.085)\end{array}$ & $\begin{array}{c}0.007 \\
(0.067)\end{array}$ & $\begin{array}{c}0.037 \\
(0.058)\end{array}$ \\
\hline Gross capital formation & & & & $\begin{array}{c}0.458 \\
(0.074)\end{array}$ & $\begin{array}{c}0.411 \\
(0.064)\end{array}$ \\
\hline Schooling & & & & $\begin{array}{c}0.233 \\
(0.076)\end{array}$ & $\begin{array}{c}0.31 \\
(0.067)\end{array}$ \\
\hline Institutions & & & & & $\begin{array}{l}1.2 \\
(0.206)\end{array}$ \\
\hline Openness (SW-WW) & & $\begin{array}{l}0.14 \\
(0.051)\end{array}$ & & & \\
\hline Openness (trade share) & & & $\begin{array}{c}0.234 \\
(0.058)\end{array}$ & $\begin{array}{r}-1.303 \\
(0.385)\end{array}$ & $\begin{array}{r}-2.214 \\
(0.366)\end{array}$ \\
\hline Population & & & & $\begin{array}{r}-0.686 \\
(0.184)\end{array}$ & $\begin{array}{r}-1.108 \\
(0.174)\end{array}$ \\
\hline Openness $\times$ population & & & & $\begin{array}{c}0.118 \\
(0.039)\end{array}$ & $\begin{array}{c}0.213 \\
(0.037)\end{array}$ \\
\hline Observations & 100 & 100 & 100 & 100 & 100 \\
\hline$\sigma_{e}$ & 0.2 & 0.194 & 0.186 & 0.136 & 0.117 \\
\hline Adj. $R^{2}$ & 0.606 & 0.631 & 0.659 & 0.818 & 0.864 \\
\hline$F$ & 77.2 & 57.51 & 64.96 & 64.59 & 80.09 \\
\hline
\end{tabular}

Notes: Standard errors in parentheses. All variables are in natural logs.

dummy, whose coefficient is positive and significant. Its introduction in the regression improves the fit in a minor way, leaving the coefficients of the other covariates virtually unchanged. Only self-similarity reduces its significance. When we substitute the $S W-W W$ dummy with trade share the coefficient increases and the fit of the regression improves. The self-similarity coefficient becomes however statistically insignificant once controlling for the degree of openness with the trade share variable. The loss of significance of the selfsimilarity variable, while EU-similarity maintains its own, corroborates the conjecture that it is not a change in the export composition per se that matters for catching-up, but that the direction of change is what matters most.

\section{Adding Controls: Investment, Schooling, Institution and Size}

To overcome the missing variable bias and test for the robustness of this relation, in regressions (4) and (5) we introduce some control variables that in the empirical literature are normally associated with growth. The sign and the significance of the variables in our control group are as expected. The share of investments over GDP, the percentage of population with secondary education in 1993 and the quality of institutions (here measured using the 1999 EBRD transition index (EBRD, 2000)) are all usually positively 
associated with a higher speed of catching-up. In our regression they indeed appear positive and significant, and they improve the fit of the regression.

The introduction of these control variables changes the sign of the openness variable, which appears to be less robustly related to convergence than trade structure. Holding constant the value of other covariates, openness per se shows a negative and significant impact on catching-up. This is an important feature of our countries' data. In general, openness measured by the share of exports and imports over GDP - could just capture the role played by the size of a country in its growth process (Alesina et al., 2005), so it is necessary to disentangle the two different effects, examining the possible interaction among the two variables. Therefore, measuring country size with population and taking it as a the moderator variable and openness as the moderated variable, in the last two columns of Table 2 we show that the direct effect of openness on the process of catching-up is negative, when the size of the country is small, while the interaction of the two variables foster convergence. Larger open countries do catch-up faster and the quality of institutions enhances this process.

The introduction of the EBRD index as a measure of the quality of institutions has two more effects on the coefficients of other covariates, it reduces the role of similarity (EU-similarity remains significant but its coefficient shrinks, while self-similarity looses its significance) and increases the one of openness and population. Once controlling for the quality of institutions, openness by itself is influencing even more negatively income convergence in small countries, while when controlling for the size of the country the opposite is true.

\section{Robustness}

In regressions (6) and (7) in Table 3, we test for the presence of outliers. Two of them - Latvia and Lithuania in 1993 - were identified by Cook's test and excluded. Results are qualitatively the same but the fit of the regression improves.

As a further control of these results we modify our specification by introducing countries' dummies to control for unobserved countries' characteristics resulting in a different intercept for every different country in our panel. ${ }^{5}$ In regression (8), the use of countries' dummies reduces the effect of EU-similarity, makes the self-similarity coefficient significant and therefore considerably improves the goodness of fit. However, this procedure can also introduce potential problems of multicollinearity with the time invariant factor variables of schooling and institutions. ${ }^{6}$

After having checked for non-normally distributed errors, collinearity, and heteroskedasticity the information conveyed by regression (8) is that our main result is fully confirmed: the index of EU similarity is always positive and significant. 
Table 3. Robustness checks. Dependent variable is country's per capita GDP relative to EU15 per capita GDP

\begin{tabular}{lcccccc}
\hline & $O L S$ & $O L S$ & $O L S$ & $I V(b)$ & $I V(b)$ & $I V(b)$ \\
& $(6)$ & $(7)$ & $(8)$ & $(9)$ & $(10)$ & $(11)$ \\
\hline Intercept & 12.18 & 14.47 & 14.52 & 15.55 & 15.14 & 18.27 \\
& $(1.64)$ & $(1.44)$ & $(1.23)$ & $(2.20)$ & $(1.84)$ & $(2.14)$ \\
EU-similarity & 0.857 & 0.664 & 0.475 & 0.714 & 0.512 & \\
& $(0.053)$ & $(0.055)$ & $(0.057)$ & $(0.080)$ & $(0.084)$ & \\
EU-correlation & & & & & & 0.198 \\
Self-similarity & & & & & & $(0.029)$ \\
& -0.151 & -0.107 & -0.141 & -0.177 & -0.210 & \\
Self-correlation & $(0.067)$ & $(0.057)$ & $(0.049)$ & $(0.088)$ & $(0.076)$ & \\
& & & & & & -0.164 \\
Gross capital formation & 0.475 & 0.426 & 0.280 & 0.399 & 0.261 & $0.067)$ \\
& $(0.066)$ & $(0.057)$ & $(0.054)$ & $(0.049)$ & $(0.046)$ & $(0.046)$ \\
Schooling & 0.301 & 0.363 & 0.619 & 0.364 & 0.631 & 0.701 \\
& $(0.069)$ & $(0.059)$ & $(0.067)$ & $(0.056)$ & $(0.064)$ & $(0.074)$ \\
Institutions & & 1.101 & 1.651 & 1.066 & 1.605 & 1.680 \\
& & $(0.182)$ & $(0.182)$ & $(0.234)$ & $(0.177)$ & $(0.160)$ \\
Openness (trade share) & -1.706 & -2.504 & -2.774 & -2.704 & -2.888 & -3.646 \\
& $(0.351)$ & $(0.325)$ & $(0.281)$ & $(0.470)$ & $(0.377)$ & $(0.437)$ \\
Population & -0.84 & -1.213 & -1.385 & -1.309 & -1.445 & -1.787 \\
& $(0.166)$ & $(0.154)$ & $(0.135)$ & $(0.214)$ & $(0.174)$ & $(0.198)$ \\
Openness $\times$ population & 0.147 & 0.232 & 0.289 & 0.252 & 0.302 & 0.377 \\
& $(0.035)$ & $(0.033)$ & $(0.030)$ & $(0.045)$ & $(0.037)$ & $(0.042)$ \\
Country dummies & & & yes & & yes & yes \\
Observations & $98(\mathrm{a})$ & $98(\mathrm{a})$ & $98(\mathrm{a})$ & 90 & 90 & 90 \\
$\sigma_{\mathrm{e}}$ & 0.121 & 0.102 & 0.087 & 0.102 & 0.088 & 0.086 \\
Adj. $R^{2}$ & 0.857 & 0.897 & 0.932 & 0.907 & 0.931 & 0.935 \\
$F$ & 84.17 & 107.2 & 134.4 & 143.4 & 289.34 & 255.68 \\
\hline
\end{tabular}

Notes: Standard errors in parentheses. All variables are in natural logs.

(a) Outliers excluded; (b) 2SLS with robust standard errors, instruments are openness, EUsimilarity and self-similarity lagged one period. In regression (11) instruments are openness, EU-correlation and self-correlation lagged one period.

In regressions (9), (10) and (11) we also address the problem of simultaneity between openness and income levels (Frenkel \& Romer, 1999) by instrumenting openness via a one-period lag in a two-stages leastsquares regression with robust standard errors. Since one could suspect that EU-similarity and self-similarity may also be endogenous to various degrees, we instrumented them analogously. No relevant changes in the parameter estimates or in their significance has been noticed, ${ }^{7}$ and the results are confirmed also when country dummies are introduced in the regression.

Finally, we also check for the influence that the specific similarity index used in the analysis could have had on the results of the regression, substituting the similarity metric derived from the Bray-Curtis distance index, $s_{x y}$, with the Pearson linear correlation index.

We run the regression using again a two-stages least-squares estimator, instrumenting openness, EU-correlation and self-correlation as in the 
previous cases, and including country dummies. No qualitative change in the results has been noticed. ${ }^{8}$

\section{Nonlinearity}

The presumption of a nonlinear effect of EU-similarity on convergence induced by the observation of the characteristics of the contour plot of the joint distribution of per capita GDP and EU-similarity makes necessary a supplement of inquiry about the relationship between the two variables. The first strategy adopted, takes as a starting point the result obtained by introducing country dummies in the previous regressions. The positive and significant effect of the dummy confirms the still existing heterogeneity of the CEECs once controlling for the influence of the covariates on $G D P_{j t}$. Our hypothesis is that the explanation of this remaining heterogeneity lies in the nonlinearity of the relation between $E U$-similarity and $G D P_{j t}$ due to the different behavior of countries at different levels of EU-similarity.

Therefore, we split the $E U$-similarity variable into two equally numerous groups of 49 observations (excluding outliers), defining a dummy variable indicating a 'high' level of EU-similarity or a 'low' level of EU-similarity. We could run regressions of convergence on EU-similarity and openness, separately for 'high' EU-similarity and 'low' EU-similarity countries, in order to test whether the coefficient on the EU-similarity variable is significantly different from zero, and whether it is significantly more positive for 'high' EU-similarity countries. However, a more efficient way of testing the robustness of our result is to pool all countries together, and estimate the following regression equation:

$$
\begin{aligned}
& \text { Ln } G D P_{j t}=\beta_{0}+\beta_{1} \ln E U \text {-similarity } \text { sit }+\beta_{2} \ln \text { Self-similarity }_{j t} \\
& +\beta_{3} \ln \text { openness }_{t}+\beta_{4} \text { HighEU-similarity }_{j t}+\mathbf{X}_{j t} \gamma+u_{j t}
\end{aligned}
$$

The results of the regression are contained in Table 4, and confirm what we presumed: the positive and significant coefficients for $E U$-similarity and High EU-similarity indicate that a different intercept and a different marginal slope of the regression are significant and that the relationship between EU-similarity and the catching-up process is nonlinear. ${ }^{9}$ This corroborates the simple evidence of Figure 3 of the existence of a multiple regime.

It is important to notice that in regression (12) the EU-similarity coefficient is still positive and significant, as it is the coefficient indicating the marginal effect of the quality of institutions on $G D P_{j t}$; however, both coefficients have been remarkably reduced in size by the introduction of the EU-similarity dummy in the regression. Such a reduction indicates that, on the one hand, being similar to the EU in terms of export composition 
Table 4. Nonlinearity. Dependent variable is country's per capita GDP relative to EU15 per capita GDP

\begin{tabular}{lccc}
\hline & $\begin{array}{c}O L S \\
(12)\end{array}$ & $\begin{array}{c}I V(b) \\
(13)\end{array}$ & $\begin{array}{c}\text { Spline } \\
(14)\end{array}$ \\
\hline Intercept & 11 & 9.40 & 8.65 \\
& $(1.35)$ & $(1.83)$ & $(1.57)$ \\
EU-similarity & 0.328 & 0.203 & see Figure 3 \\
Self-similarity & $(0.073)$ & $(0.110)$ & \\
& -0.157 & -0.329 & -0.126 \\
Gross capital formation & $(0.049)$ & $(0.071)$ & $(0.052)$ \\
& 0.375 & 0.229 & 0.313 \\
Schooling & $(0.049)$ & $(0.045)$ & $(0.056)$ \\
& 0.447 & 0.571 & 0.376 \\
Institutions & $(0.052)$ & $(0.070)$ & $(0.067)$ \\
& 0.5 & -0.030 & 0.545 \\
Openness (trade share) & $(0.184)$ & $(0.155)$ & $(0.196)$ \\
& -1.695 & -1.183 & -1.282 \\
Population & $(0.307)$ & $(0.388)$ & $(0.371)$ \\
& -0.853 & -0.622 & $(0.638$ \\
Openness $\times$ population & $(0.143)$ & $(0.170)$ & 0.112 \\
High EU-similarity dummy & 0.159 & 0.111 & $(0.037)$ \\
Observations & $(0.030)$ & $(0.034)$ & \\
$\sigma_{\mathrm{e}}$ & 0.308 & 0.515 & $98(\mathrm{a})$ \\
Adj. $R^{2}$ & $(0.051)$ & $(0.070)$ & 0.09 \\
$F$ & $98(\mathrm{a})$ & 90 & 0.929 \\
& 0.086 & 0.071 & 103.1 \\
\hline
\end{tabular}

Notes: Standard errors in parentheses. All variables are in natural logs.

(a) Outliers excluded; (b) 2SLS with robust standard errors, instruments are openness, EUsimilarity and self-similarity lagged one period. In regression 11 instruments are openness, EUcorrelation and self-correlation lagged one period.

matters, but it matters most for the CEECs that are above a certain EUsimilarity threshold. On the other hand, countries highly similar to the EU export composition are characterized by better institutions.

When the same functional form is estimated using a two-stages least squares regression with robust standard errors, these results emerge even more sharply: both coefficients are not significant. The effect of institutions on $G D P_{j t}$ is entirely caught by the EU similarity dummy, while being similar to the EU export composition is irrelevant for countries not similar enough to the same composition of exports.

The limit of regression (12) - and, similarly, of regression (13) - is that the construction of the High EU-similarity dummy variable is somehow arbitrary. The selection criteria of halving the observations in two perfectly proportional groups along the EU-similarity dimension cannot be the most appropriate one. So we follow Durlauf and Johnson (1995) in extracting the most appropriate criteria directly from the data itself. Instead of using a tree-regression approach as in Durlauf and Johnson (1995), we use an additive semi-parametric regression, as in Liu and Stengos (1999), which 


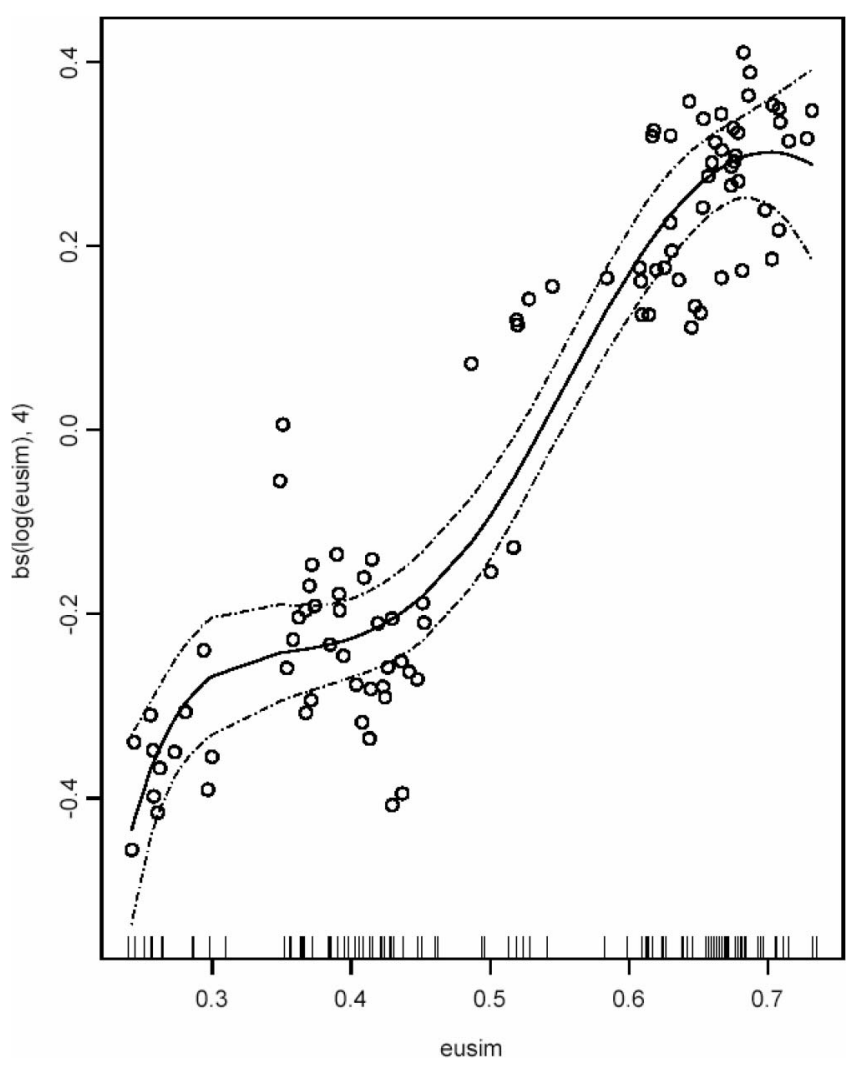

Figure 3. Marginal effect of EU-similarity on catching-up

allows us to do some standard inference. The resulting regression equation is:

$$
\begin{aligned}
\text { Ln } G D P_{j t}= & \beta_{0}+g\left(\ln \text { EU }_{\text {-similarity }}\right)+\beta_{2} \ln \text { self-similarity }_{j t} \\
& +\beta_{3} \ln \text { openness }_{j t}+\mathbf{X}_{j t} \gamma+u_{j t}
\end{aligned}
$$

Since we assume only one non-parametric term, the structural form of equation (3) replicates the partial regression model studied by Robinson (1988) and Speckman (1988). The only difference with respect to regression (1) is that the variable EU-similarity does not enter the equation linearly. $g$ (ln EU-similarity) is an unknown function that in our case takes the form of a smoothing spline ${ }^{10}$ (Hastie \& Tibshirani, 1999), with the smooth term modeled using polynomial regression splines. ${ }^{11}$

Results are included in the last column of Table 4. As for as the partial effect of EU-similarity on convergence, the result of the semi-parametric regression is plotted in Figure 3, where the estimated function is the analog 
of the estimated coefficient in linear regressions. The existence of a multiple regime is again significant and robust to the introduction of several different controls. Moving from the left edge of the covariate space, convergence rapidly increases, flattening down at a second stage, and rising again at high levels of EU-similarity. With respect to our discussion of the results in regression (12), now it is perfectly evident that EU-similarity in export composition seems to be more effective only after a certain threshold is reached More formally, the Anova test strongly rejected the hypothesis of a linear marginal effect of EU-similarity on catching-up. The second main result of our analysis is therefore that similarity in trade structure always matters for convergence, but as similarity becomes higher the effect on convergence is magnified. In other words, a multiple regime exists among the CEECs' convergence toward the EU's per capita GDP, and being similar to the sectoral export composition of EU countries as suppliers for the EU market seems to be the discriminatory factor separating converging countries from non-converging ones.

\section{Conclusions}

Both empirical evidence and theoretical models suggest that the relationship between trade and growth might be a contingent one, depending on a host of specific circumstances. Trade models indicate that different models of specialization have diversified effects on factors' prices and therefore factors' accumulation, suggesting that one of the specific circumstances affecting the trade and growth relationship might indeed be the patter of trade. In this paper we test this hypothesis for the case of the CEECs and the EU.

The CEECs have been converging toward the EU income levels during the 1990s at different speeds. The EU is also the main trade partner of these countries, and the export flows from these countries toward the EU market have been increasing, but these flows displayed different characteristics. Our empirical analysis shows that a measure of export similarity between the CEECs and the EU is positively and significantly associated with the convergence process of these countries in terms of income: the CEECs whose export composition is closer to the EU enjoyed a faster catching-up process. Results also show that this impact is nonlinear, yet it is robust controlling for investment, schooling, and the quality of institutions.

Theoretical analyses suggest distinct reasons behind this result, but the proper mechanism driving the observed link needs to be further explored. In fact, a closer economic integration might in principle bring about further changes in trade structures, and affect the convergence path between countries. This is a very sensitive issue in the integration process. In the EU, income convergence is one of the main challenges, as wide gaps in income levels and living standards among members can put strain on the whole process of European integration. This could also be true in other circumstances of integration between countries at different stages of 
development. Further research should therefore also consider whether these results for the CEECs and the EU could be generalized.

\section{Acknowledgments}

The authors wish to thank Fabio Sdogati, Lelio Iapadre and the participants at the conferences Economic Growth and Distribution held in Lucca, June 2004, and ETSG 2004 in Nottingham, as well as two anonymous referees for comments and suggestions. Financial support from MIUR, PRIN prot. 2002138555 is gratefully acknowledged.

\section{Notes}

${ }^{1}$ To a large extent, integration though trade flows was achieved well before the formal entry of the CEECs into the EU (Landesmann, 2003).

2 The Bray-Curtis semi-metric - largely used in the natural sciences - is a bounded measure, $0 \leq d_{x y} \leq 1$; it has the advantage of not increasing in the number of sectors considered, $n$; of being invariant to proportional sub-classifications of the $n$ sectors considered; it is not subject to the double-zeros paradox; it lessens the effect of the largest differences since difference in high sectoral export shares contribute the same as differences between small sectoral export shares; and is appropriate in the presence of skewed distributions. Therefore $d_{x y}$ has been selected as our preferred choice. We also make use of the linear correlation index $r_{x y}$ in the multivariate regression in order to verify the robustness of the empirical evidence to different measures of similarity.

3 A standard approach would be 'to cut' the bivariate kernels at equally spaced heights regardless of the 'depth' of the observations; in the present case, the contours have been carefully drawn in order to contain specific proportions of the dataset. The contour labeled ' 75 ' contains the 75 per cent of the observations, and similarly for the contours labeled ' 50 ' and ' 25 '.

${ }^{4}$ The Sachs \& Warner - Wacziarg \& Welch index (SW-WW) classifies countries as open if they satisfy all the following five criteria: (1) the average of unweighted tariffs in the 19901999 period is lower than 40 per cent; (2) the average of core non-tariff barriers on capital goods and intermediates is lower than 40 per cent; (3) the average black market premium over the period is lower than 20 per cent; (4) the country does not have an export marketing board; and (5) the country is not socialist.

${ }^{5}$ A possible alternative is to use country fixed or random effects, but since our emphasis (as will be shown) is on the use of a semi-parametric regression, in order to give robust evidence of the nonlinear effect of EU-similarity on the catch-up of CEECs, and since, as pointed out by a referee, the literature on fixed and random effect semi-parametric regression is not thoroughly developed and proper tests to discriminate between fixed and random effects alternatives are still unavailable, we opted for a simpler functional form with a country categorical predictor, so as to allow for comparison of parametric and semi-parametric regressions.

${ }^{6}$ The exclusion of potentially collinear variables (not shown) increases the significance of the country dummy parameter, increasing the $F$ value of the regression.

${ }^{7}$ Since there is a presumption of a serial correlation in openness we also used the first difference of the variable as an instrument. In this case the magnitude of the coefficients changes, but the sign and the significance remain stable.

8 The parameter estimate for EU-correlation is substantially lower than the one for EUsimilarity; the explanation lies on the insensitiveness of the correlation index to specific 


\section{L. De Benedictis \& L. Tajoli}

relative changes in the export structure of countries. The disadvantages in the use of the Pearson correlation index as a measure of similarity in trade structures are discussed in De Benedictis and Tajoli (2007).

${ }^{9}$ Diagnostics have been applied to the functional form of regression (12) with positive results.

${ }^{10}$ Splines are piece-wise polynomial functions that fit together at 'knots' (Hastie \& Tibshirani, 1999: 22); for cubic splines - as in our case - the first and second derivatives are also continuous at the knots.

${ }^{11}$ Smoothing splines arise as the solution to the following simple-regression problem: find the function $\hat{f}(x)$ with two continuous derivatives that minimizes the penalized sum of squares, $S S^{*}(h)=\sum_{i=1}^{n}\left[y_{i}-f\left(x_{i}\right)\right]^{2}+\int_{x_{\max }}^{x_{\max }}\left[f^{\prime \prime}\left(x_{i}\right)\right]^{2} \mathrm{~d} x$ where $h$ is a smoothing parameter. The first term in the previous equation is the residual sum of squares. The second term is a roughness penalty, which is large when the integrated second derivative of the regression function $f^{\prime \prime}(x)$ is large - that is, when $f(x)$ is rapidly changing slope. The endpoints of the integral enclose the data.

\section{References}

Alesina A. et al. (2005) Trade, growth and the size of countries, in: P. Aghion and S. Durlauf (Eds) Handbook of Economic Growth, 1(B), pp. 1499-1542 (Elsevier).

Baldwin, R. E. (2004) Openness and growth: what is the empirical relationship? in: R. E. Baldwin and A. Winters (Eds) Challenges to Globalization (Chicago, IL: NBER, University of Chicago Press).

Ben-David, D. and Kimhi, A. (2000) Trade and the rate of income convergence. NBER WP n. 7642.

Ben-David, D. and Loewy, M. B. (1998) Free trade, growth and convergence, Journal of Economic Growth, 3(2).

Bensidoun, I. et al. (2001) The nature of specialization matters for growth: an empirical investigation. CEPII Working Paper 2001-13.

Crespo Cuaresma, J. and Wörz, J. (2005) On export composition and growth, Weltwirtschaftliches Archiv, 141(1).

De Benedictis, L. and Tajoli, L. (2007) Economic integration and similarity in trade structures, Empirica, forthcoming.

Dollar, D. (1992) Outward-oriented developing economies really do grow more rapidly: evidence from 95 LDCs, 1976-1985, Economic Development and Cultural change, 40, pp. $523-544$.

Durlauf, S. N. (2003) The convergence hypothesis after 10 years. University of Wisconsin at Madison Economics Department Working Paper 2003-6.

Durlauf, S. N. and Johnson, P. A. (1995) Multiple regimes and cross-country growth behaviour, Economic Journal, 108, pp. 383-398.

Durlauf, S. N. and Quah, D. T. (1999) The new empirics of economic growth, in: J. Taylor and M. Woodford (Eds) Handbook of Macroeconomics, Chapter 4, 1(1), pages 235-308 (Elsevier).

EBRD (2000) EBRD Transition Report 2000: Employment, skills, and transition.

Edwards, S. (1998) Openness, productivity and growth: what do we really know?, Economic Journal, 108, pp. $383-398$.

European Commission (2004) Catching-up, growth and convergence of the new Member States, European Economy, Chapter 2 in the EU Economy 2004 Review, No. 6 (Office for Official Publications of the EC. Luxembourg).

Feenstra, R. C. and Rose, A. K. (2000) Putting things in order: patterns of trade dynamics and growth, The Review of Economics and Statistics, 82(3), pp. 369-382.

Frankel, J. and Romer, D. (1999) Does trade cause growth?, American Economic Review, 89, pp. $379-399$.

Hallak, J. C. and Levinsohn, J. (2004) Fooling ourselves: evaluating the globalization and growth debate, NBER Working paper 10244. 
Hastie, T. J. and Tibshirani, R. J. (1999) Generalized Additive Models (Chapman and Hall).

Imbs J. (2004) Trade, finance, specialization, and synchronization, The Review of Economics and Statistics, 86(3), pp. $723-734$.

Imbs, J. (1999) Co-Fluctuations, CEPR Discussion Papers 2267.

Imbs, J. and Wacziarg, R. (2003) Stages of diversification, American Economic Review, 93(1), pp. $63-86$.

Kose, M. A. and Yi, K.-M. (2006) Can the standard international business cycle model explain the relation between trade and comovement?, Journal of International Economics, 68(2), pp. $267-295$.

Landesmann, M. A. (2003) Structural features of economic integration in an enlarged Europe: patterns of catching-up and industrial specialization. European Commission Economic paper 181.

Lederman, D. and Maloney, W. F. (2003) Trade structure and growth. World Bank Policy Research Working Paper 3025.

Linder, S. (1961) An Essay on Trade and Transformation (Uppsala: Almqvist and Wiksells).

Liu, Z. and Stengos, T. (1999) Non-linearities in cross-country growth regressions: a semiparametric approach, Journal of Applied Econometrics, 14, pp. 527-538.

Markusen, J. R. (1986) Explaining the volume of trade: an eclectic approach, American Economic Review, 76(5), pp. 1002-1011.

Quah, D. T. (1997) Empirics for growth and distribution: stratification, polarization, and convergence clubs, Journal of Economic Growth, 2, pp. 27-59.

Rivera-Batiz, L. A. and Romer, P. (1991) Economic integration and endogenous growth, Quarterly Journal of Economics, 106, pp. 531-555.

Robinson, P. M. (1988) Root-N-consistent semiparametric regression, Econometrica, 56(4), pp. $931-954$.

Rodriguez, F. and Rodrik, D. (2000) Trade policy and economic growth: a skeptic's guide to the cross-national evidence, in: B. Gernanke and K. Rogoff (Eds) NBER Macroeconomics Annual (Cambridge: MIT Press).

Rodrik, D. et al. (2005) What you export matters, NBER Working Paper 11905, December.

Sachs, J. and Warner, A. (1995) Economic reform and the process of global integration, Brookings Papers on Economic Activity, 1, pp. 1-118.

Sachs, J. and Warner, A. (1999) The big push, natural resource booms and growth, Journal of Development Economics, 59, pp. 43-76.

Slaughter, M. J. (1997) Per capita income convergence and the role of international trade, American Economic Review, 87(2).

Speckman, P. (1988) Kernel smoothing in partial linear models, Journal of the Royal Statistical Society, Series B, 50(3), pp. 413-436.

Ventura, J. (1997) Growth and interdependence, Quarterly Journal of Economics, 107, pp. 57 - 84. van de Klundert T. and Smulders, S. (1996) North-South knowledge spillovers and competition: convergence versus divergence, Journal of Development Economics, 50(2), pp. $213-395$.

Wacziarg, R. and Welch, K. H. (2003) Trade liberalization and growth: new evidence. NBER Working Paper 10152.

Young, A. (1991) Learning by doing and the dynamic effects of international trade, Quarterly Journal of Economics, 106.

\section{Appendix - Data sources}

Export composition is calculated using data from Eurostat, Comext database on Intra and extra EU trade, adopting the Combined Nomenclature classification. 
Openness is calculated as exports + imports/GDP using data from Eurostat, Statistics in Focus, or alternatively is the openness dummy from Sachs and Warner (1995) updated by Wacziarg and Welch (2003).

Income gap between the CEECs and the EU is calculated as the ratio between the CEEC GDP per capita and the average EU-15 GDP per capita both in PPS, taken from Eurostat, Statistics in Focus, Economy and Finance.

Gross capital formation is taken from Eurostat, Statistics in Focus.

Population is taken from Eurostat, Statistics in Focus.

Schooling refers to the percentage of population with secondary education in 1993 (or initial available year) and it is taken from ILO Laborsta database.

The Transition index is taken from the EBRD, Transition report 2000. 